\title{
Valve repair versus valve replacement for degenerative mitral valve disease
}

\author{
A. Marc Gillinov, MD, ${ }^{a}$ Eugene H. Blackstone, MD, a,b Edward R. Nowicki, MD, ${ }^{a}$ Worawong Slisatkorn, MD, ${ }^{a}$ \\ Ghannam Al-Dossari, MD, ${ }^{a}$ Douglas R. Johnston, MD, ${ }^{a}$ Kristopher M. George, MD, ${ }^{a}$ Penny L. Houghtaling, MS, \\ Brian Griffin, MD, ${ }^{\mathrm{c}}$ Joseph F. Sabik, III, MD, ${ }^{\mathrm{a}}$ and Lars G. Svensson, MD, PhD ${ }^{\mathrm{a}}$
}

Supplemental material is available online.

Earn CME credits at http:// cme.ctsnetjournals.org
From the Departments of Thoracic and Cardiovascular Surgery, ${ }^{\mathrm{a}}$ Quantitative Health Sciences, ${ }^{\mathrm{b}}$ and Cardiovascular Medicine, Cleveland Clinic, Cleveland, Ohio.

Supported in part by the Judith Dion Pyle Chair in Heart Valve Research (A.M.G.), the Kenneth Gee and Paula Shaw, PhD, Chair in Heart Research (E.H.B.), and the John and Rosemary Brown Endowed Chair in Cardiovascular Medicine (B.G.). Dr Gillinov reports fees from Edwards, Medtronic, St Jude, Atricure, and Boston Scientific, and research support from Medtronic and St Jude. Dr Sabik reports fees from Medtronic.

Read at the Eighty-seventh Annual Meeting of The American Association for Thoracic Surgery, Washington, DC, May 5-9, 2007.

Received for publication May 2, 2007; revisions received Oct 15, 2007; accepted for publication Nov 26, 2007.

Address for reprints: A. Marc Gillinov, MD, Department of Thoracic and Cardiovascular Surgery, Cleveland Clinic, 9500 Euclid Avenue/F24, Cleveland, OH 44195 (E-mail: gillinom@ccf.org).

J Thorac Cardiovasc Surg 2008;135:885-93 $0022-5223 / \$ 34.00$

Copyright $(0) 2008$ by The American Association for Thoracic Surgery

doi:10.1016/j.jtcvs.2007.11.039
Objective: The study objective was to identify characteristics differentiating patients undergoing valve replacement versus valve repair for degenerative mitral valve disease and to use this information to compare survival and reoperation after each procedure.

Methods: From 1985 to 2005, 3286 patients underwent isolated primary operation for degenerative mitral valve disease. Valve repair was performed in 3051 patients $(93 \%)$, and valve replacement was performed in 235 patients (7.2\%). A propensity model and score developed for fair comparison of outcomes yielded 195 matched pairs.

Results: Patients undergoing replacement were older ( $70 \pm 12$ years vs $57 \pm 13$ years $)$ and had more complex valvar pathology, symptoms, and left ventricular dysfunction. Thus, the characteristics of the propensity-matched patients undergoing repair more resembled those of the patients undergoing replacement (older, complex valvar pathology) than patients undergoing typical repair. Eight patients died in the hospital $(0.26 \%)$ after repair and 5 patients $(2.1 \%)$ died after replacement $(P=.001)$. Unadjusted survival at 5,10 , and 15 years was $95 \%, 87 \%$, and $68 \%$ after repair and $80 \%, 60 \%$, and $44 \%$ after replacement, respectively $(P<.0001)$; however, among propensity-matched patients, survival was similar $(P=.8): 86 \%$ versus $83 \%$ at 5 years, $63 \%$ versus $62 \%$ at 10 years, and $43 \%$ versus $48 \%$ at 15 years. Freedom from reoperation among propensity-matched patients was $94 \%$ at 5 and 10 years after repair and $95 \%$ and $92 \%$ at 5 and 10 years after replacement, respectively $(P=.6)$.

Conclusion: It is reasonable to perform valve repair in elderly patients with complex degenerative mitral valve pathology because it can eliminate the need for anticoagulation and risk of prosthesis-related complications. However, when valve pathology is so complex that repair is infeasible, this study demonstrates that valve replacement does not diminish long-term outcomes.

$\mathrm{T}$ The reported advantages of mitral valve repair over mitral valve replacement include preservation of left ventricular function; greater freedoms from endocarditis, thromboembolism, and anticoagulant-related hemorrhage; and, most important, improved survival. ${ }^{1-5}$ For these reasons, valve repair is preferred to valve replacement in patients with degenerative mitral valve disease ${ }^{6}$ However, there are few data available to clarify the relative effects of patient factors and choice of valve procedure (repair vs replacement) on outcome after surgery for mitral regurgitation (MR) caused by degenerative disease. Selected patients with rheumatic and ischemic MR seem to have equal, and in some cases better, survival with valve replacement as with valve repair, illustrating the importance of patient characteristics on outcome. ${ }^{7,8}$ In patients with degenerative MR, we sought to 1 ) identify characteristics differentiating those undergoing valve replacement from those undergoing valve repair, 2) use this information to compare, among matched patients, survival and reoperation after each procedure, and 3) contrast these outcomes with those of typical patients undergoing valve repair. 


\section{Abbreviation and Acronym \\ $\mathrm{MR}=$ mitral regurgitation}

\section{Materials and Methods Study Population}

From January of 1985 to January of 2005, 3286 patients with isolated degenerative mitral valve disease underwent surgery for MR. Repair was performed in 3051 patients (93\%), and replacement was performed in 235 patients (7\%). Sixty-four patients had unsuccessful repair that was converted to replacement during the initial operation; for the main treatment-received analyses, these patients were considered to be in the replacement group, and for secondary analyses of crossover to replacement, these patients were considered to be in the repair group (intent to treat). Patients having concomitant coronary artery bypass grafting, aortic valve disease, hypertrophic cardiomyopathy, or ascending aortic aneurysm were excluded. The results in subsets of these patients have been reported. ${ }^{1}$ Concomitant tricuspid valve repair for functional tricuspid regurgitation was performed in 171 patients (5.2\%), and ablation of atrial fibrillation was performed in 153 patients (4.6\%).

Preoperative MR was graded by echocardiography using standard techniques; all patients had moderately severe $(3+, 8.2 \%)$ or severe $(4+, 92 \%)$ MR. Data were extracted from the Cardiovascular Information Registry, a repository of extensive clinical and surgical data entered concurrently with patient care. Use of these data for research was approved by the institutional review board, with patient consent waived.

\section{Surgical Technique}

Surgical approach was minimally invasive in 1726 patients, full sternotomy in 1552 patients, and right thoracotomy in 4 patients. The minimally invasive technique included a $6-$ to 8 -cm skin incision and partial upper sternotomy. ${ }^{9}$ The most common repair techniques included posterior leaflet resection with (1244) or without (1466) sliding repair and chordal transfer (423). Anuloplasty techniques included Cosgrove-Edwards anuloplasty band (Edwards Lifesciences LLC, Irvine, Calif) (2254, 74\%), Carpentier-Edwards classic ring (Edwards Lifesciences LLC) $(411,13 \%)$, and posterior bovine pericardial strip (296, 9.7\%); 90 patients $(2.9 \%)$ had leaflet repair without anuloplasty. Among 235 patients undergoing mitral valve replacement, prostheses were bioprosthetic in 179 (76\%) and mechanical in 56 (24\%). At mitral valve replacement, the posterior leaflet and its attached subvalvar apparatus were routinely preserved; the anterior leaflet generally was excised.

\section{Follow-up}

Patients were followed routinely at 2, 5, 10, 15, and 20 years. At each follow-up, patients were contacted by mailed institutional review board-approved questionnaire or telephone interview, with patient consent. Follow-up for mitral valve reoperation depended entirely on this active follow-up. Of the 3286 patients, 897 were not yet due for follow-up. Of the remaining 2389 patients, 303 (13\%) were considered lost to follow-up (269 US and 29 foreign patients were untraced, and 5 patients did not consent to follow-up). The median active follow-up was 2.6 years, with $25 \%$ followed more than 5.6 years, $10 \%$ followed $\geq 10$ years, and $3 \%$ followed $\geq 12$ years; 11,689 patient-years of data were available for analyses of reoperation. Information on vital status was supplemented by data from the Social Security Death Index ${ }^{10,11}$ (cross-sectional passive follow-up), yielding a total of 18,244 patient-years of data for analysis. Passive follow-up averaged $5.6 \pm 4.4$ years, with $15 \%$ of living patients followed $\geq 10$ years and $5 \%$ followed $\geq 14$ years. Graphs of reoperation were truncated at 12 years, and graphs of survival were truncated at 14 years.

\section{Data Analysis}

Factors Associated With Mitral Valve Replacement Versus Repair. Multivariable logistic regression was performed to identify factors associated with mitral valve replacement versus repair. Variables considered are listed in Appendix 1. Bagging was the method for variable selection, with automated analysis of 500 resampled data sets, followed by tabulating the frequency of occurrence at $P \leq .05$ of both single factors and closely related clusters of factors. ${ }^{10,11}$ Factors with occurrence of $50 \%$ or more were retained in the model.

Time-related Events. Nonparametric time-to-event estimates were obtained by the Kaplan-Meier method. For mortality, a parametric method was used to resolve the number of phases of instantaneous risk (hazard function) and estimate shaping parameters. ${ }^{12}$ (For additional details, see http://www.clevelandclinic.org/heartcenter/ hazard.) Thereafter, multivariable analyses were performed in the hazard function domain. Variable selection used bagging, as described earlier.

Outcomes in Propensity-matched Pairs. Because the characteristics of patients receiving mitral valve replacement rather than repair were different (Table 1), propensity score methods were used to reduce selection bias in comparing outcomes. ${ }^{13,14}$ First, logistic regression analysis was used to identify risk factors for valve replacement rather than repair, using bagging as described earlier in the text. Second, this parsimonious model was amplified by nonstatistically significant variables representing every class of variable available, 28 in all. Third, by using the resulting propensity model, a propensity score representing the probability of having a replacement was estimated for each patient (Figure E1). Fourth, on the basis of the propensity scores, 195 matched pairs were identified. ${ }^{15}$ Finally, time-related outcomes were compared between matched patients receiving repair and patients receiving replacement.

Survival in Unmatched Patients. Of 235 patients receiving replacement, $40(17 \%)$ could not be matched to 1 of the 3051 patients undergoing repair because the distribution of propensity scores for the majority of those receiving repair was distinctively different from that of those receiving replacement (Figure E1). Thus, we present the characteristics and survival of unmatched patients in both groups. $^{14}$

Accounting for Attempted Repairs. The influence of attempted valve repair, converted to replacement in the same operation, was assessed in 2 ways. First, among propensity-matched pairs, the variable "attempted repair" (crossover from repair to replacement in same operative session) was added to the multivariable survival model used to compare valve repair versus replacement. Second, matched patients were compared as strictly intent-to-treat.

Presentation. Mortality, survival, and freedom from reoperation estimates are accompanied by asymmetric $68 \%$ confidence limits equivalent to \pm 1 standard error. Categoric data are summarized 
TABLE 1. Characteristics of patients undergoing mitral repair versus replacement

\begin{tabular}{|c|c|c|c|c|c|}
\hline \multirow[b]{2}{*}{ Characteristic } & \multicolumn{2}{|c|}{ MV repair } & \multicolumn{2}{|c|}{ MV replacement } & \multirow[b]{2}{*}{$\boldsymbol{P}$} \\
\hline & $\mathbf{n}^{*}$ & No. $(\%)$ & $\mathbf{n}^{*}$ & No. $(\%)$ & \\
\hline \multicolumn{6}{|l|}{ Demography } \\
\hline Women & 3051 & $966(32)$ & 235 & $116(49)$ & $<.0001$ \\
\hline Age (y) & 3051 & $57 \pm 13$ & 235 & $70 \pm 11$ & $<.0001$ \\
\hline \multicolumn{6}{|l|}{ Symptoms } \\
\hline NYHA class & 3051 & & 235 & & $<.0001$ \\
\hline I & & $885(29)$ & & $34(14)$ & \\
\hline II & & $1741(57)$ & & $133(57)$ & \\
\hline III & & $369(12)$ & & $61(26)$ & \\
\hline IV & & $56(1.8)$ & & $7(3.0)$ & \\
\hline \multicolumn{6}{|l|}{ Mitral valve pathophysiology } \\
\hline MV prolapse & 3051 & & 235 & & $<.0001$ \\
\hline Posterior & & $2530(83)$ & & $100(43)$ & \\
\hline Anterior & & $233(7.6)$ & & $52(22)$ & \\
\hline Bileaflet & & $288(9.4)$ & & $83(35)$ & \\
\hline MV calcification & 3051 & $671(22)$ & 235 & $112(48)$ & $<.0001$ \\
\hline \multicolumn{6}{|l|}{ Cardiac structure and function } \\
\hline LA diameter $(\mathrm{cm})$ & 2564 & $4.9 \pm 0.91$ & 185 & $5.3 \pm 1.02$ & $<.0001$ \\
\hline LVEF (echocardiogram, \%) & 2291 & $58 \pm 7.5$ & 169 & $56 \pm 8.3$ & .0005 \\
\hline LV inner diameter in diastole $(\mathrm{cm})$ & 2664 & $5.8 \pm 0.81$ & 188 & $5.6 \pm 0.93$ & .0008 \\
\hline LV inner diameter in systole $(\mathrm{cm})$ & 2650 & $3.5 \pm 0.75$ & 188 & $3.4 \pm 0.86$ & .7 \\
\hline Posterior wall thickness (cm) & 2593 & $1.1 \pm 0.19$ & 189 & $1.2 \pm 0.21$ & $<.0001$ \\
\hline \multicolumn{6}{|l|}{ Comorbidity } \\
\hline Atrial fibrillation/flutter & 3051 & $475(16)$ & 235 & $78(33)$ & $<.0001$ \\
\hline PAD & 2864 & $200(7.0)$ & 208 & $38(18)$ & $<.0001$ \\
\hline COPD & 2216 & $290(13)$ & 150 & $36(24)$ & .0002 \\
\hline Hypertension & 2938 & $1055(36)$ & 227 & $104(46)$ & .003 \\
\hline Treated diabetes & 2952 & 44 (1.5) & 233 & $9(3.9)$ & .006 \\
\hline Stroke & 3051 & $61(2.0)$ & 235 & $13(5.5)$ & .0004 \\
\hline
\end{tabular}

$C O P D$, Chronic obstructive pulmonary disease; $L V$, left ventricular; $L A$, left atrial; $L V E F$, left ventricular ejection fraction; $M V$, mitral valve; $N Y H A$, New York Heart Association; $P A D$, peripheral arterial disease. *Data available.

by frequencies and percentages, and continuous variables are summarized by means \pm 1 standard deviation.

\section{Results}

Factors Associated With Replacement Versus Repair

The probability of performing mitral valve repair rather than replacement increased during the first few years of this experience, stabilizing at approximately $95 \%$ during the last 15 years (Figure 1, A). Patients undergoing replacement were older $(70 \pm 12$ years vs $57 \pm 13$ years, Figure $1, B)$ and had more advanced symptoms, with $29 \%$ showing New York Heart Association functional class III or IV versus $14 \%$ of patients undergoing repair (Table 1). Advanced age, mitral valve calcification, anterior or bileaflet prolapse, operation earlier in the experience, and surgeon identity were associated with an increased probability of replacement rather than repair (Table 2). These characteristics of patients undergoing valve replacement were not typical of most patients presenting for management of degenerative mitral valve disease, as illustrated by the more favorable profile of unmatched patients undergoing repair (Table 3).

\section{Overall Survival}

There were 13 hospital deaths $(0.4 \%), 8$ in patients undergoing repair $(0.26 \%$; confidence limit $0.17 \%-0.39 \%)$ and 5 in patients undergoing replacement $(2.1 \%$, confidence limit $1.2 \% \%-3.5 \%)(P=.001)$. Unadjusted survival estimates at $1,5,10$, and 15 years were $98 \%, 95 \%, 87 \%$, and $68 \%$ after repair and $92 \%, 80 \%, 60 \%$, and $44 \%$ after replacement, respectively $(P<.0001)$. For patients undergoing repair, survival was superior to that of an age-sex-matched US population; for patients undergoing replacement, survival was equivalent to the matched US population after an initial high-risk phase postoperatively (Figure 2).

\section{Survival in Propensity-matched Patients}

Among propensity-matched pairs, survival was similar after both replacement and repair $(P=.9$; Figure 3$)$. This finding was corroborated by propensity-adjusted multivariable analysis (Table E1). Among these propensity-matched groups, survival was similar to that of the age and sex-matched US population after a period of higher risk early after operation in both groups. 

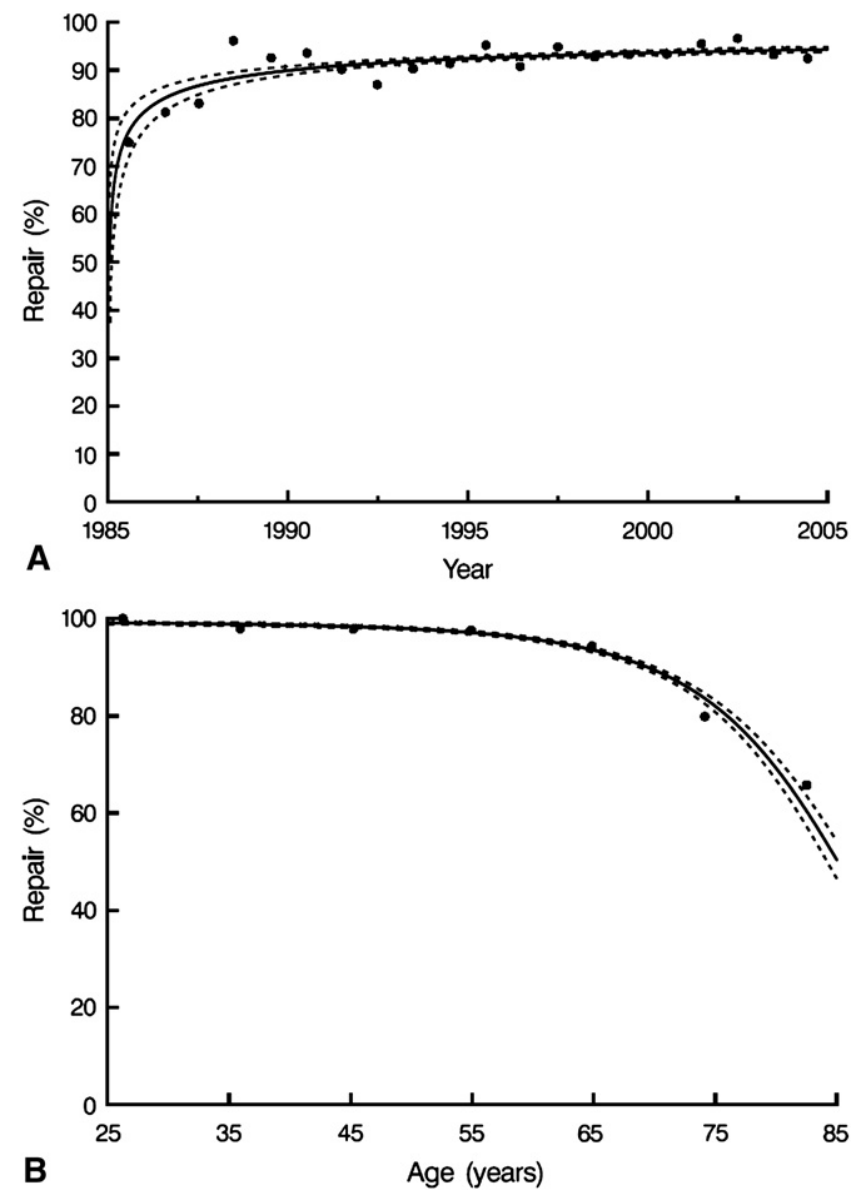

Figure 1. Factors associated with mitral valve repair versus replacement. Raw grouped frequencies (closed circles) and trend (solid line). A, Time trend for mitral valve repair. B, Age trend for mitral valve repair.

\section{Survival in Unmatched Patients}

Survival was greater in patients undergoing repair who could not be matched to patients undergoing replacement (Figure 4); these represent typical patients undergoing repair (Table 3): young with no or mild symptoms, generally in sinus rhythm, and having isolated posterior leaflet prolapse without valve calcification. Survival was lowest in unmatched patients undergoing replacement, who were older $(75 \pm 8.1$ years), were more symptomatic, were more likely to be in atrial fibrillation and have noncardiac comorbidities, and rarely had isolated posterior mitral leaflet prolapse $(7.5 \%)$, but rather anterior or bileaflet prolapse and mitral valve calcification. These comparisons were similar by multivariable analysis of attempted repair $(P>.5$, Table E1) and intentto-treat analyses $(P>.6)$.

\section{Freedom from Reoperation}

Among propensity-matched patients, there were 21 mitral valve reoperations, 10 in the repair group and 11 in the re-
TABLE 2. Factors associated with type of mitral valve surgery

\begin{tabular}{lrccc}
\hline \multicolumn{1}{c}{ Factors } & Estimate \pm SE & $\boldsymbol{P}$ & $\begin{array}{c}\text { Reliability } \\
(\%)^{*}\end{array}$ \\
\hline $\begin{array}{l}\text { Associated with replacement } \\
\text { Older age }\end{array}$ & $1.26 \pm 0.111$ & $<.0001$ & 100 \\
Anterior or bileaflet prolapse & $2.1 \pm 0.178$ & $<.0001$ & 82 \\
MV calcification & $1.09 \pm 0.173$ & $<.0001$ & 90 \\
Surgeon A & $2.2 \pm 0.56$ & $<.0001$ & 58 \\
Surgeon B & $2.1 \pm 0.38$ & $<.0001$ & 83 \\
Surgeon C & $1.54 \pm 0.55$ & .005 & 54 \\
Associated with repair & & & \\
More recent date & $-0.033 \pm 0.0162$ & .04 & 65 \\
$\quad$ of operation & & & \\
Surgeon D & $-1.44 \pm 0.179$ & $<.0001$ & 99 \\
\hline
\end{tabular}

$M V$, Mitral valve; $S E$, standard error. *Percent of occurrences in 500 bootstrap models.

placement group (8/144 who received a bioprosthetic and $3 / 51$ who received a mechanical prosthesis). Actuarial freedom from reoperation was similar $(P=.9)$ among these groups (Figure 5).

\section{Discussion}

\section{Key Findings}

In an institution where mitral valve repair is distinctly preferred, patients undergoing valve replacement rather than repair for degenerative MR are older and sicker, with complex mitral valve pathology and multiple comorbidities. Both groups, however, experienced long-term survival commensurate with that of the general population. At this end of the spectrum, survival and freedom from mitral valve reoperation were similar after repair or replacement, including a period of higher early postoperative risk.

\section{Factors Associated With Mitral Valve Replacement versus Repair}

The primary objective of this study was to determine the impact of mitral valve repair versus replacement on survival and reoperation in patients with degenerative disease. However, examination of the data revealed important differences between these patient groups. Patients undergoing valve replacement were more likely to have complex valvar pathology, including calcification and anterior or bileaflet prolapse; these factors increase the difficulty of valve repair. Although most replacements occurred in this group, our data also demonstrate that the majority of such valves are repairable, and previous studies document excellent long-term durability after repair. ${ }^{2,3,16,17}$ Patients with this complex valvar pathology represent a distinct subgroup of those presenting for surgical management of degenerative mitral valve disease; they are older and have more symptoms and comorbidities, including atrial fibrillation for which they are already 
TABLE 3. Characteristics of patients undergoing mitral repair versus replacement: Matched and unmatched groups

\begin{tabular}{|c|c|c|c|c|}
\hline \multirow[b]{2}{*}{ Characteristic } & \multicolumn{2}{|c|}{ MV repair } & \multicolumn{2}{|c|}{ MV replacement } \\
\hline & Unmatched $(n=2856)$ & Matched $(n=195)$ & Matched $(n=195)$ & Unmatched $(n=40)$ \\
\hline \multicolumn{5}{|l|}{ Demography } \\
\hline Women & $869(30)$ & $97(50)$ & $91(47)$ & $25(62)$ \\
\hline Age (y) & $56 \pm 12$ & $69 \pm 10$ & $69 \pm 11$ & $75 \pm 8.1$ \\
\hline \multicolumn{5}{|l|}{ Symptoms } \\
\hline \multicolumn{5}{|l|}{ NYHA class } \\
\hline I & $859(30)$ & $26(13)$ & $30(15)$ & $4(10)$ \\
\hline II & $1629(57)$ & $112(57)$ & $112(57)$ & $21(52)$ \\
\hline III & $318(11)$ & $51(26)$ & $47(24)$ & $14(35)$ \\
\hline IV & $50(1.7)$ & $6(3.1)$ & $6(3.1)$ & $1(2.5)$ \\
\hline \multicolumn{5}{|l|}{ Mitral valve pathophysiology } \\
\hline \multicolumn{5}{|l|}{ MV prolapse } \\
\hline Posterior & $2435(85)$ & $95(49)$ & $97(50)$ & $3(7.5)$ \\
\hline Anterior & $190(6.6)$ & $43(22)$ & $37(19)$ & $15(37)$ \\
\hline Bileaflet & $231(8.1)$ & $57(29)$ & $61(31)$ & $22(55)$ \\
\hline MV calcification & $582(20)$ & $89(46)$ & $88(45)$ & $24(60)$ \\
\hline \multicolumn{5}{|l|}{ Cardiac structure and function } \\
\hline LA diameter $(\mathrm{cm})$ & $4.9 \pm 0.91$ & $5.2 \pm 0.92$ & $5.3 \pm 1.05$ & $5.2 \pm 0.87$ \\
\hline LVEF (echocardiogram, \%) & $58 \pm 7.4$ & $55 \pm 8.5$ & $55 \pm 8.8$ & $55 \pm 5.8$ \\
\hline LV inner diameter in diastole $(\mathrm{cm})$ & $5.8 \pm 0.80$ & $5.6 \pm 0.87$ & $5.7 \pm 0.89$ & $5.2 \pm 1.04$ \\
\hline LV inner diameter in systole $(\mathrm{cm})$ & $3.5 \pm 0.74$ & $3.4 \pm 0.85$ & $3.5 \pm 0.84$ & $3.2 \pm 0.90$ \\
\hline Posterior wall thickness (cm) & $1.10 \pm 0.190$ & $1.12 \pm 0.20$ & $1.2 \pm 0.21$ & $1.13 \pm 0.190$ \\
\hline \multicolumn{5}{|l|}{ Comorbidity } \\
\hline Atrial fibrillation/flutter & $410(14)$ & $65(33)$ & $60(31)$ & $18(45)$ \\
\hline $\mathrm{PAD}^{*}$ & $165 / 2701(6.1)$ & $35 / 163(21)$ & 29/175 (17) & $9 / 33(27)$ \\
\hline COPD & $267 / 2095(13)$ & 23/121 (19) & $27 / 121(22)$ & $9 / 29(31)$ \\
\hline Hypertension & $974 / 2751(35)$ & $81 / 187(43)$ & $83 / 187(44)$ & $21(52)$ \\
\hline Treated diabetes & $38 / 2763(1.4)$ & $6 / 189(3.2)$ & $5 / 193(2.6)$ & $4(10)$ \\
\hline Stroke & $50(1.7)$ & $11(5.6)$ & $9(4.6)$ & $4(10)$ \\
\hline
\end{tabular}

$C O P D$, Chronic obstructive pulmonary disease; $L A$, left atrial; $L V$, left ventricular; $L V E F$, left ventricular ejection fraction; $M V$, mitral valve; $N Y H A$, New York Heart Association; $P A D$, peripheral arterial disease. *Denominator represents the number of observations for which values for variables were available.

receiving warfarin, and more likely to have left ventricular dysfunction, as previously shown by David and colleagues. ${ }^{3}$ It is only in these patients that we could compare outcomes after mitral valve repair and replacement. In particular, our data do not enable comparison of outcomes after valve repair versus replacement in the typical young patient in sinus rhythm with isolated posterior leaflet prolapse, few symptoms, and no comorbidity, because few patients with this profile undergo replacement at our institution.

The wide disparity of characteristics of patients undergoing repair and replacement, particularly in settings such as ours that are committed to repair, calls into question unadjusted comparisons of outcomes after surgery for degenerative mitral valve disease. ${ }^{2,4,18,19}$ For example, analyzing 1411 patients with mitral valve prolapse undergoing repair $(83 \%)$ or replacement $(17 \%)$, Suri and colleagues focused on the site of prolapse and claimed to demonstrate a survival benefit of repair over replacement in patients with isolated posterior or bileaflet prolapse. ${ }^{2}$ Patients in that study were older and more symptomatic than the typical patient undergo- ing valve repair, and many also had coronary artery disease. The presence of coronary artery disease introduces complex confounding of results, complicating analyses. ${ }^{20}$ Risk-adjusted comparison of repair and replacement in that setting indicated that repair usually (89\%) conferred a survival advantage. $^{21}$

\section{Mitral Repair versus Replacement: Outcomes}

Surgical correction of degenerative MR, whether by repair or replacement, was associated with long-term survival either better than (repair) or similar to (replacement) that of the general US population. Although unadjusted survival was better after repair than replacement, propensity-matched groups undergoing repair and replacement had similar survival and freedom from reoperation. This finding does not negate the generally accepted tenet that mitral valve repair is preferable to replacement in most patients with degenerative mitral valve disease and has excellent long-term durability. ${ }^{1-6}$ Rather, these data enhance our understanding of the roles of mitral valve repair and replacement in the 


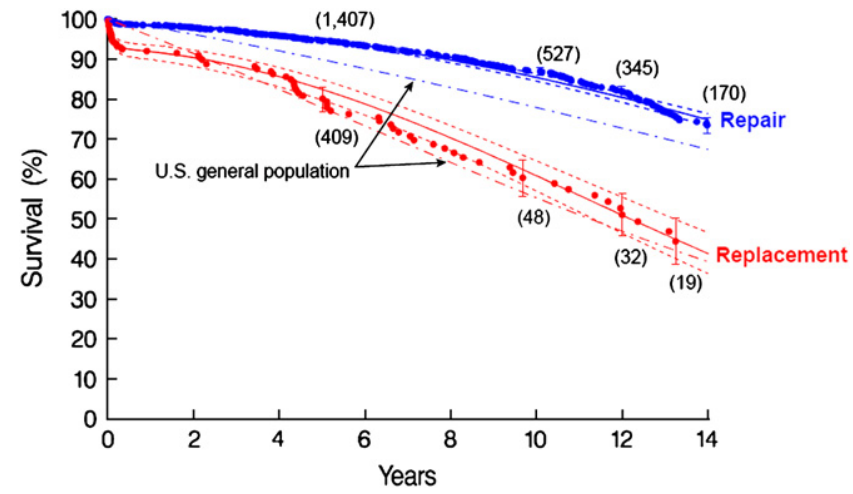

Figure 2. Unadjusted survival after mitral valve repair (b/ue) or replacement (red) compared with age and sex-matched US population (dot-dash curves). Each symbol represents a death, and vertical bars are $68 \%$ actuarial confidence limits. Numbers in parentheses represent patients remaining at risk. Solid lines are parametric survival estimates enclosed within dashed $68 \%$ confidence limits.

subgroup of patients with complex valvar pathology. When a valve either appears unrepairable or attempts to repair fail, neither survival nor reoperation is adversely affected by replacement.

\section{Limitations}

This is a single-institution study of operations performed during a 20-year time span. However, repair techniques have remained nearly constant, and valve replacement has included chordal sparing since the late 1980s. This study addresses survival and, to a lesser extent, reoperation after surgery for degenerative mitral valve disease; we did not seek to examine effects of mitral procedure on other outcomes, such as freedom from prosthesis-related morbidity.

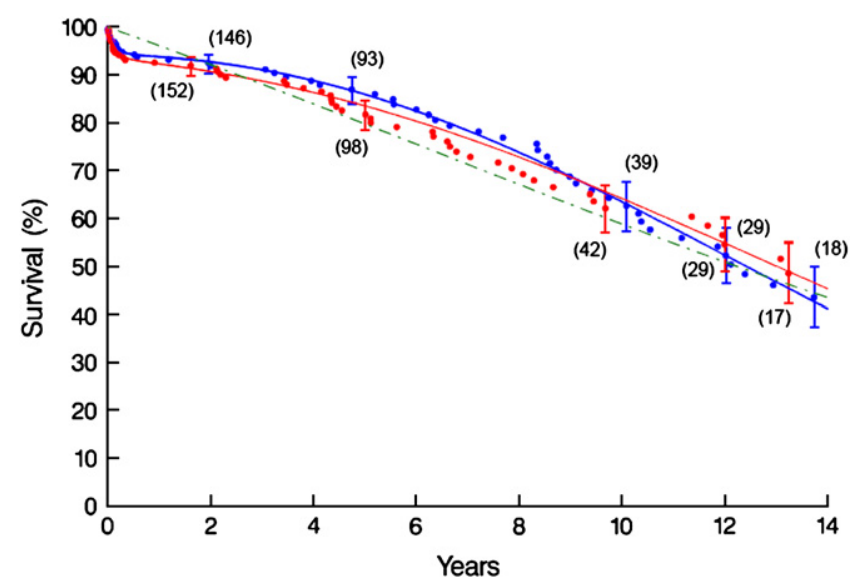

Figure 3. Survival in propensity-matched patients having repair (blue) or replacement (red) compared with age-sex-matched US population (green). Format is as in Figure 2.

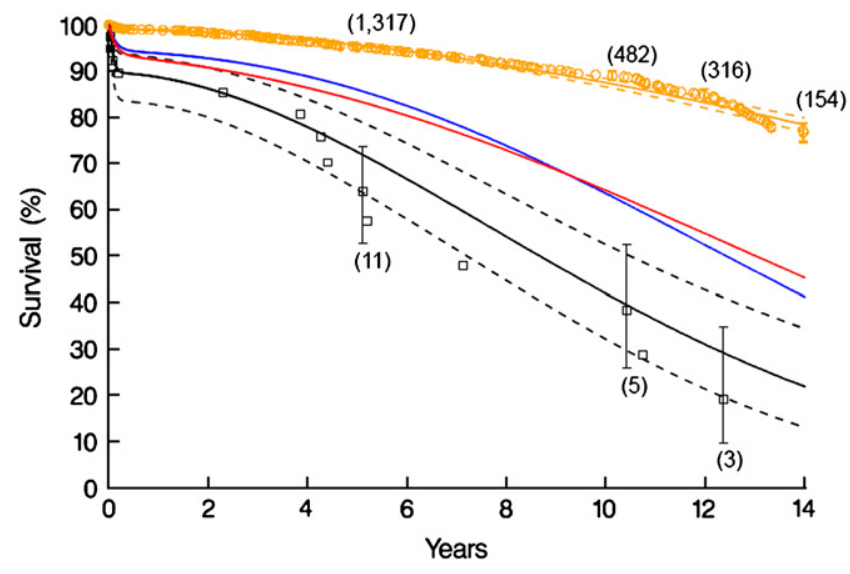

Figure 4. Survival in propensity-matched patients having repair (blue) or replacement (red) compared with unmatched patients having repair (orange) or replacement (black). Format is as in Figure 2.

This is not a randomized trial. At this point in the history of mitral valve surgery, such a trial involving patients with typical degenerative disease is likely infeasible. Rather, the choice of surgical procedure and its conduct were surgeondependent; for this reason, surgeon identity was included in the analyses. This revealed that even in our institution some surgeons are somewhat more likely than others to elect valve replacement over valve repair.

The small number of valve replacements among typical younger patients with degenerative disease prohibited assessing the effect of repair versus replacement in that group. Therefore, comparative survival analyses may apply only

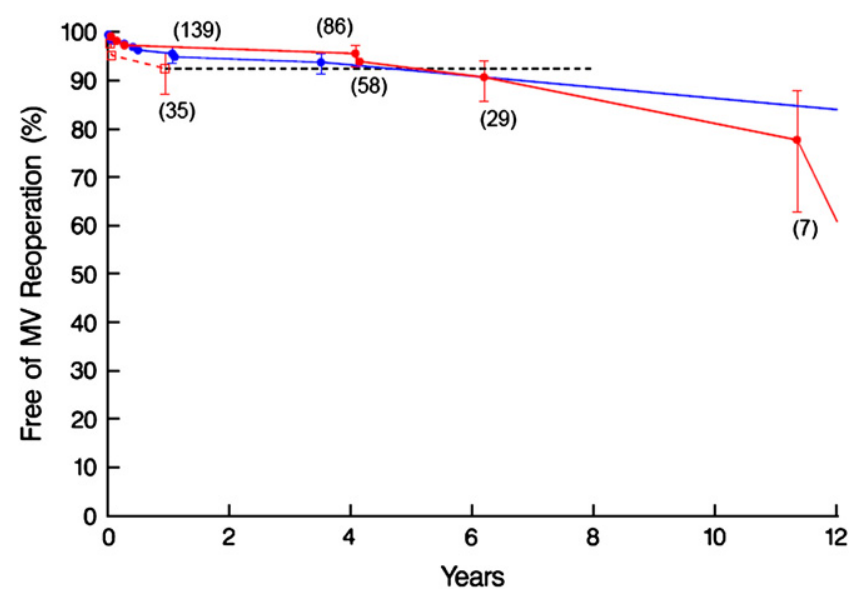

Figure 5. Reoperation in propensity-matched patients after mitral valve repair (blue), replacement with bioprosthetic valve (red), or replacement with mechanical valve (black). Format of actuarial estimates is as in Figure 2. 
to patients with complex valvar pathology, who tend to be older and have greater comorbidity.

\section{Conclusions}

Mitral valve repair is the procedure of choice for patients with isolated degenerative valve disease, most of whom will be relatively young, at most mildly symptomatic, and in sinus rhythm with well-preserved left ventricular function and only posterior leaflet prolapse. Mitral valve repair preserves the native valve, has excellent durability, and spares the patient from known adverse events of prosthetic heart valves. It is reasonable to also consider valve repair in elderly patients and in those with complex prolapse and valvar calcification, particularly those in sinus rhythm, because this can eliminate the need for anticoagulation and risk of prosthesisrelated complications. If such a patient is also in atrial fibrillation, we now recommend mitral valve repair plus surgical ablation of atrial fibrillation. ${ }^{22}$ However, when valvar pathology is so severe that repair is infeasible, valve replacement does not diminish long-term survival.

The authors thank Songhua Lin, MS, for statistical programming; Karen Mrazeck, Deborah Gladish, Tanya Ashinhurst, Wanda Weaver, and Patricia White for follow-up; and Tess Parry for editorial assistance.

\section{References}

1. Gillinov AM, Cosgrove DM, Blackstone EH, Diaz R, Arnold JH, Lytle BW, et al. Durability of mitral valve repair for degenerative disease. J Thorac Cardiovasc Surg. 1998;116:734-43.

2. Suri RM, Schaff HV, Dearani JA, Sundt TM 3rd, Daly RC, Mullany CJ, et al. Survival advantage and improved durability of mitral repair for leaflet prolapse subsets in the current era. Ann Thorac Surg. 2006;82: 819-26.

3. David TE, Ivanov J, Armstrong S, Christie D, Rakowski H. A comparison of outcomes of mitral valve repair for degenerative disease with posterior, anterior, and bileaflet prolapse. J Thorac Cardiovasc Surg. 2005; 130:1242-9.

4. Mohty D, Orszulak TA, Schaff HV, Avierinos JF, Tajik JA, EnriquezSarano M. Very long-term survival and durability of mitral valve repair for mitral valve prolapse. Circulation. 2001;104:I1-7.

5. Braunberger E, Deloche A, Berrebi A, Abdallah F, Celestin JA, Meimoun P, et al. Very long-term results (more than 20 years) of valve repair with Carpentier's techniques in nonrheumatic mitral valve insufficiency. Circulation. 2001;104:I8-11.

6. Bonow RO, Carabello BA, Chatterjee K, de Leon AC Jr, Faxon DP, Freed MD, et al. ACC/AHA 2006 guidelines for the management of patients with valvular heart disease: a report of the American College of Cardiology/American Heart Association Task Force on Practice Guidelines (writing Committee to Revise the 1998 guidelines for the management of patients with valvular heart disease) developed in collaboration with the Society of Cardiovascular Anesthesiologists endorsed by the Society for Cardiovascular Angiography and Interventions and the Society of Thoracic Surgeons. J Am Coll Cardiol. 2006;48:e1-148.

7. Gillinov AM, Wierup PN, Blackstone EH, Bishay ES, Cosgrove DM, White $\mathrm{J}$, et al. Is repair preferable to replacement for ischemic mitral regurgitation? J Thorac Cardiovasc Surg. 2001;122:1125-41.

8. Grossi EA, Galloway AC, Miller JS, Ribakove GH, Culliford AT, Esposito R, et al. Valve repair versus replacement for mitral insufficiency: when is a mechanical valve still indicated? J Thorac Cardiovasc Surg. 1998;115:389-96.
9. Gillinov AM, Cosgrove DM. Minimally invasive mitral valve surgery: mini-sternotomy with extended transseptal approach. Semin Thorac Cardiovasc Surg. 1999;11:206-11.

10. Breiman L. Bagging predictors. J Mach Learn Res. 1996;24:123-40.

11. Blackstone EH. Breaking down barriers: helpful breakthrough statistical methods you need to understand better. J Thorac Cardiovasc Surg. 2001;122:430-9.

12. Blackstone EH, Naftel DC, Turner ME Jr. The decomposition of timevarying hazard into phases, each incorporating a separate stream of concomitant information. J Am Stat Assoc. 1986;81:615-24.

13. Rosenbaum PR, Rubin DB. The central role of the propensity score in observational studies for causal effects. Biometrika. 1983;70:41-55.

14. Blackstone EH. Comparing apples and oranges. J Thorac Cardiovasc Surg. 2002;123:8-15.

15. Bergstralh EJ, Konsanke JL. Computerized Matching of Cases to Controls. Technical report No. 56. Department of Health Science Research. Rochester, MN: Mayo Clinic; 1995.

16. Carpentier AF, Pellerin M, Fuzellier JF, Relland JY. Extensive calcification of the mitral valve anulus: pathology and surgical management. J Thorac Cardiovasc Surg. 1996;111:718-30.

17. Grossi EA, Galloway AC, Steinberg BM, LeBoutillier M 3rd, Delianides J, Baumann FG, et al. Severe calcification does not affect long-term outcome of mitral valve repair. Ann Thorac Surg. 1994;58: 685-8.

18. Perier P, Deloche A, Chauvaud S, Fabiani JN, Rossant P, Bessou JP, et al. Comparative evaluation of mitral valve repair and replacement with Starr, Bjork, and porcine valve prostheses. Circulation. 1984;70: I187-92.

19. Shuhaiber J, Anderson RJ. Meta-analysis of clinical outcomes following surgical mitral valve repair or replacement. Eur J Cardiothorac Surg. 2007;31:267-75.

20. Gillinov AM, Blackstone EH, Rajeswaran J, Mawad M, McCarthy PM, Sabik JF 3rd, et al. Ischemic versus degenerative mitral regurgitation: does etiology affect survival? Ann Thorac Surg. 2005;80:811-9.

21. Gillinov AM, Faber C, Houghtaling PL, Blackstone EH, Lam BK, Diaz R, et al. Repair versus replacement for degenerative mitral valve disease with coexisting ischemic heart disease. $J$ Thorac Cardiovasc Surg. 2003;125:1350-62.

22. Gillinov AM, McCarthy PM, Blackstone EH, Pettersson G, Calhoun R, Sabik JF, et al. Bipolar radiofrequency to ablate atrial fibrillation in patients undergoing mitral valve surgery. Heart Surg Forum. 2004;7: E147-52.

\section{Appendix 1. Variables used in multivariable analyses}

\section{Demography}

Age $(\mathrm{y})$, sex, height $(\mathrm{cm})$, weight $(\mathrm{kg})$, body surface area $\left(\mathrm{m}^{2}\right)$, body mass index $\left(\mathrm{kg} / \mathrm{m}^{-2}\right)$

\section{Preoperative Status}

New York Heart Association functional class, Canadian angina class, emergency operation

\section{Mitral Valve Pathology}

Leaflet prolapse (posterior, anterior, bileaflet), valve fibrosis or thickening, valve calcification, elongated chordae (posterior, anterior), chordal rupture (posterior, anterior), elongated papillary muscle, dilatation of mitral anulus, dilated left ventricle, regurgitation grade ( 0 to $4+$ scale), left atrial diameter, and volume

\section{Left Ventricular Structure and Function}

LV mass $\left(\mathrm{g} / \mathrm{m}^{-2}\right), \mathrm{LV}$ inner diameter in diastole $(\mathrm{cm}), \mathrm{LV}$ end-diastolic volume $(\mathrm{mL}), \mathrm{LV}$ inner diameter in systole 
(cm), LV end-systolic volume (mL), posterior wall thickness $(\mathrm{cm})$, intraventricular septal thickness $(\mathrm{cm}), \mathrm{LV}$ relative wall thickness, $\mathrm{LV}$ dysfunction grade $(0=$ none, $1=$ mild, $2=$ moderate, $3=$ severe), previous myocardial infarction, $\mathrm{LV}$ ejection fraction $(\%)$

\section{Other Cardiac Comorbidity}

Atrial fibrillation, coronary artery stenosis ( $\geq 50 \%$, any) (left main trunk, left anterior descending coronary artery, circumflex coronary artery, right coronary artery), number of coronary systems with $>50 \%$ stenosis, family history of coronary artery disease, ventricular arrhythmia, complete heart block, history of endocarditis, history of heart failure

\section{Noncardiac Comorbidity}

History of hypertension, treated diabetes (insulin treated/not insulin treated), stroke, smoking; peripheral arterial disease, chronic obstructive pulmonary disease, renal failure, blood urea nitrogen $\left(\mathrm{mg} / \mathrm{dL}^{-1}\right)$, creatinine $\left(\mathrm{mg} / \mathrm{dL}^{-1}\right)$, bilirubin $\left(\mathrm{mg} / \mathrm{dL}^{-1}\right)$, cholesterol $\left(\mathrm{mg} / \mathrm{dL}^{-1}\right)$ (total, high-density lipoprotein, low-density lipoprotein), triglycerides $\left(\mathrm{mg} / \mathrm{dL}^{-1}\right)$, hematocrit $(\%)$

\section{Details of Procedure}

Surgical approach (minimally invasive), mitral valve repair details (posterior/anterior/bileaflet repair, leaflet resection, sliding leaflet repair, chordal resection, cleft repair, leaflet suture, leaflet debridement, type of anuloplasty ring), mitral valve replacement details (mechanical or bioprosthetic, propensity for replacement), tricuspid valve repair

\section{Experience}

Date of operation, surgeon

$L V$, Left ventricular.

\section{Discussion}

Dr T. David (Toronto, Canada). This is another thought-provoking study from the Cleveland Clinic surgeons. I have to confess that when I first read the abstract last January, I questioned the validity of the conclusion and immediately asked our statistician to analyze our data on mitral valve surgery for MR due to degenerative disease. I had always believed that mitral valve repair was better than mitral valve replacement because of the importance of the mitral valve apparatus in left ventricular function. Moreover, prosthetic valves are far from perfect, and conventional wisdom is that they are associated with a higher risk of valve-related mortality and morbidity than valve repair.

Much to my disappointment, our statistician gave me some bad news: Our clinical outcomes as far as survival was concerned were identical to yours. Overall, patients who had mitral valve repair had better long-term survival than patients who had mitral valve replacement, but the 2 groups of patients were different, and when matched by propensity score analysis, the difference in survival disappeared. In other words, mitral valve repair did not enhance lifespan when compared with mitral valve replacement in matched patients. How- ever, as in your study, the matched patients were older, had more advanced functional classes, and had more comorbid conditions. I remain puzzled with these results, but that is what your and our data showed.

I had hoped to challenge your results, but I can't. All I can ask you is to speculate on what would the results be if we compared the outcomes of valve repair with replacement in younger, minimally symptomatic, low-risk patients, such as most that we now operate on? Also, did you determine the predictors of survival in all patients by multivariable analysis? If so, was mitral valve repair an independent predictor of survival?

Dr Gillinov. As to the first question, this relates to our preconceived notions and to beliefs about mitral valve repair that we hold dear. We still believe that mitral valve repair is the procedure of choice for degenerative disease. We do not have enough younger patients with posterior prolapse who received replacement to compare repair and replacement in that group. However, the mean age of those patients is 57 years, and I have to think that if we put a mechanical valve or a bioprosthesis in a 57-year-old, that person will be facing a quarter century of risk for prosthesis-related morbidity; I believe that repair reduces these risks. Our hope and speculation are that to have a valve repair for 25 years is superior to having a prosthesis for 25 years.

As far as survival in all patients, mitral valve repair does not emerge as a factor that increases overall survival. Rather, survival is influenced more by traditional factors, including left ventricular dysfunction, advanced age, and other comorbidities. I am not sure that we will ever be able to do a prospective study that directly addresses the survival impact of mitral valve repair when compared with replacement. It is currently not feasible to take 57-year-old people with posterior leaflet prolapse and randomize them to our best prosthesis or our best repair. So we are just going to have to come at that question from as many directions as possible using existing data.

Dr Irving Kron (Charlottesville, $\mathrm{Va}$ ). I am fearful that the message will be misinterpreted, and I am sure you have thought about this. Certainly at the Cleveland Clinic you are going to do everything you can to repair a valve. Literally less than $10 \%$ of your valves were replaced. So the typical patient who undergoes replacement in the United States probably has bileaflet prolapse and is younger. You didn't show us that group, but my suspicion would be, and certainly our bias is, that they should be repaired. What are your thoughts about this?

Dr Gillinov. We agree. The first thing Dr Lytle said to me about this topic was to be careful in framing the message of this article because a reader may look at the title, draw a conclusion about mitral valve repair, and stop there. We have carefully tried to craft the message and point out that in the patient you have described, who is younger with bileaflet prolapse, we would strive to repair that valve. In addition, we repair most degenerative valves in elderly patients. This article focuses primarily on the elderly patients with complex pathology, the group who did have enough replacements to enable comparison between repair and replacement.

Dr Thierry Mesana (Ottawa, Ontario, Canada). Did you see any difference in mortality in your 2 subsets of patients, and have you changed your policies in your institution in relation to this study? For example, what do you do when you have a posterior leaflet prolapse with a moderate level of calcification in a patient aged 80 years or more? 
Dr Gillinov. Let me answer the second question first, and this relates to the many different combinations of valvular pathology. If the valve looks repairable, we repair it, whether there is calcium, bileaflet prolapse, or anterior leaflet prolapse. If we can repair the valve, we do so. As far as mortality, I think that was one of the key messages I tried to get across. Overall, repair looks better, but when you compare matched patients, repair and replacement are similar; but those matched patients are older and sicker, with more complex conditions, and this message may not be generalizable to the typical young patients undergoing repair.

Dr David Adams (New York, NY). In your propensity-matched repairs, did calcium and bileaflet prolapse influence the success and durability of the repair over time? In other words, your repair group had calcification and bileaflet prolapse. Can you give us a sense that these repairs were durable and that you actually solved their regurgitation over time?

Dr Gillinov. I think what you are suggesting is the possibility that the matched patients undergoing repair did not do well because the repairs were not as good or as durable as more straightforward repairs. We did not look closely at durability in this study except to state that the reoperation rate, which is a crude estimate of durability, was similar after repair and replacement. Other studies (eg, Dr David's own study looking at bileaflet vs anterior and posterior leaflet prolapse) demonstrate good durability with the complex repairs but not as good as the durability with a standard P2 prolapse. Therefore, it is possible that reduced durability in complex patients may influence survival. However, statistically it is challenging to determine the relationship between 2 different outcomes of an intervention, repair durability and survival both being outcomes of the operation.

Dr Christoph Knosalla (Berlin, Germany). Because preservation of the subvalvular apparatus is also important after mitral valve replacement, I am wondering how and to what extent this has been achieved in the patients you operated on?

Dr Gillinov. That is a good question. In this cohort, virtually all of the patients undergoing replacement had preservation of the posterior leaflet and the subvalvular apparatus, but preservation of the anterior leaflet was less common.

Dr John Conte (Baltimore, $M d$ ). Many of us have been willing to accept less than perfect results for repairs in some patients because we have truly believed that repair was better. Do you think what you may have done, and some people may interpret the results of this article as such, is raised the bar for what is acceptable as a repair in a 70-year-old patient? So we might not accept a less than perfect repair in a 70-year-old patient. We might in fact use a biological valve as replacement. Your comments on that, please.

Dr Gillinov. Well, our data do not let us answer that question, but I will speculate. I think a good replacement is better than a bad repair, and I would not accept a bad repair, especially in somebody who is elderly. A good replacement is superior to a bad repair.

Dr Francis C. Wells (Cambridge, UK). As the self-help philosopher always says, the glass is either half full or half empty, and you can look at your results in another way and say that you have achieved considerably good results in a difficult group of patients. Have you had a chance to dissect out in greater detail what you were doing in the repair group in the older, sicker, more calcified group? Because to actually match a valve that is designed to be competent "off the blocks," as it were, to have the same results in that difficult group is quite an achievement.

Dr Gillinov. We have looked at these patients in greater detail. Among older patients with more complex valves, the majority received a repair. The durability of these repairs is acceptable, but not as good as durability after a standard posterior leaflet resection. If you are going to repair these valves, you need to have a good repair at the end of the day. Therefore, we leave the operating room with a selected group of patients; we leave with the ones who had a good repair confirmed by intraoperative transesophageal echocardiography. There were some patients in this series who had an attempt at repair, it failed, and they left with a replacement, and I think that that is okay, too, as long as they leave the operating room with a mitral valve that works.

Dr Bruce Lytle (Cleveland, Ohio). What is important to remember, though, is that this is a setting where surgeons believe in mitral valve repair and repair $90 \%$ of the valves in any kind of patient with degenerative valve disease who comes in, and within that setting, for that $10 \%$ of patients with complications and comorbidities, for whatever reason the valve is not repaired, it does not seem to compromise survival. We are talking about $10 \%$ of patients with degenerative valve disease at that extreme end of being difficult to repair. I think it is important we not lose sight of that. So this is a small group. 


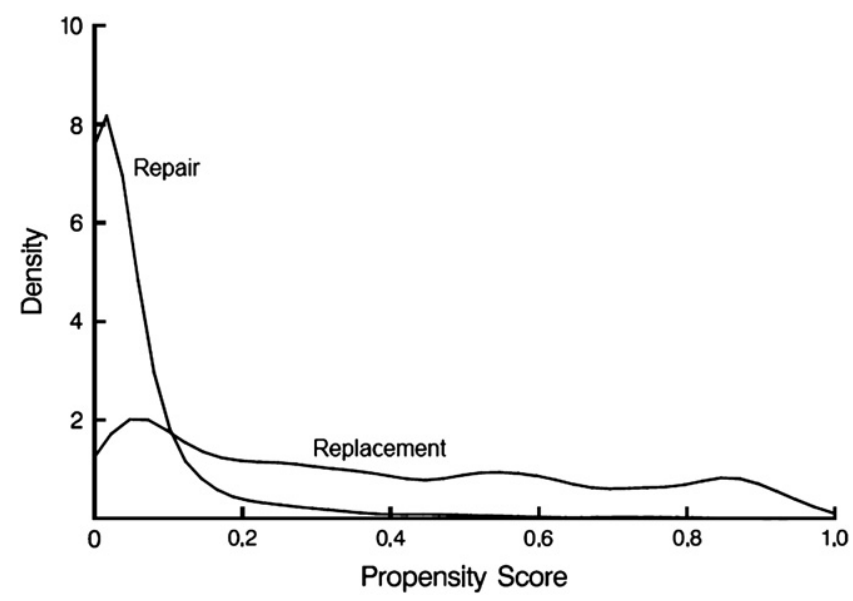

Figure E1. Distribution of propensity scores among patients undergoing mitral valve repair or replacement. 
TABLE E1. Incremental risk factors for death, adjusted for propensity

\begin{tabular}{|c|c|c|c|}
\hline Risk factor & Coefficient \pm SE & $\boldsymbol{P}$ & Reliability $(\%)^{*}$ \\
\hline \multicolumn{4}{|l|}{ Early hazard phase } \\
\hline MV replacement & $0.41 \pm 0.47$ & .4 & - \\
\hline Failed MV repair attempt & $0.27 \pm 0.60$ & 6 & - \\
\hline Propensity for replacement & $0.57 \pm 0.74$ & .4 & - \\
\hline Older age $\dagger$ & $0.85 \pm 0.21$ & $<.0001$ & 97 \\
\hline History of heart failure & $1.05 \pm 0.34$ & .002 & 66 \\
\hline LV ejection fraction & $-0.043 \pm 0.015$ & .003 & 71 \\
\hline Earlier date of operation $\ddagger$ & $0.092 \pm 0.029$ & .001 & 64 \\
\hline \multicolumn{4}{|l|}{ Late hazard phase } \\
\hline MV replacement & $0.047 \pm 0.24$ & .8 & - \\
\hline Failed MV repair attempt & $-0.23 \pm 0.38$ & .5 & - \\
\hline Propensity for replacement & $0.88 \pm 0.38$ & .02 & - \\
\hline Older age $\S$ & $5.83 \pm 0.81$ & $<.0001$ & 100 \\
\hline NYHA class III or IV & $0.36 \pm 0.14$ & .01 & 90 \\
\hline LV dysfunction (echo grade) & $0.33 \pm 0.099$ & .0009 & 85 \\
\hline Elevated bilirubin $\|$ & $0.41 \pm 0.14$ & .003 & 61 \\
\hline History of renal disease & $0.90 \pm 0.35$ & .01 & 60 \\
\hline Calcified MV & $0.33 \pm 0.14$ & .02 & 62 \\
\hline Cleft MV leaflet & $1.17 \pm 0.41$ & .005 & 59 \\
\hline
\end{tabular}

$L V$, Left ventricular; $M V$, mitral valve; $N Y H A$, New York Heart Association; $S E$, standard error. No reliable factors were found in constant hazard phase. *Percent of occurrences in 200 bootstrap models. $†$ Exp (age/50 y), exponential transformation. †़lnterval: (1/d from 1/1/85 to operation) ${ }^{2}$, inverse squared transformation. $\S \mathrm{Ln}$ (age), logarithmic transformation. ||Ln (bilirubin), logarithmic transformation. 